\title{
A Compact Dual Notch Frequency Reconfigurable Antenna for WIMAX,DSRC, RADAR and Ku band Communication Applications
}

\author{
${ }^{1,2}$ Vutukuri Sarvani Duti Rekha, ${ }^{3}$ Pokkunuri Pardhasaradhi, \\ ${ }^{3}$ Boddapati Taraka Phani Madhav, ${ }^{3}$ Yalavarthi Usha Devi
}

\author{
${ }^{1}$ Research Scholar, Department of ECE, Koneru Lakshmaiah Education Foundation, AP, India \\ ${ }^{2}$ Assistant Professor, Department of ECE, P V P Siddhartha Institute of Technology, Vijayawada, AP, India \\ ${ }^{3}$ ALRC-R\&D, Department of ECE, Koneru Lakshmaiah Education Foundation, AP, India \\ * Corresponding author's Email: btpmadhav@kluniversity.in
}

\begin{abstract}
A frequency reconfigurable ultra-wide band antenna with dual notch bands is proposed in this paper. PIN diodes are located on ultra-wide band monopole antenna and are investigated for frequency reconfigurable characteristic of the proposed antenna. Multi-bands and narrow bands have been achieved by different combinations. Proposed antenna is fabricated on FR-4 substrate of dimensions $37 \times 40 \times$ $0.8 \mathrm{~mm}^{3}$. For the successful combinations, antenna performance parameters like $S_{11}$ characteristics, surface current distribution, peak gain, radiation efficiency and 2D radiation patterns are analyzed and illustrated in the paper. Peak gain of $4.83 \mathrm{~dB}$ is obtained in operating band for D1, D2 $=0,1$ combination. Radiation efficiency is not less than $\mathbf{7 0 \%}$ in the entire operating bands. Results are analyzed experimentally for validating proposed antenna. Simulation based results and measured results are in good agreement.

Index Terms- Frequency Reconfigurable, Notch Band, Ultra-wide Band Antenna.
\end{abstract}

\section{INTRODUCTION}

Based on wireless communications, cognitive radio and software radio standards, reconfigurable antennas are becoming essential components in modern wireless communication systems. The most familiar switching components used in the design and fabrication of reconfigurable antennas are: PIN diodes, varactor diodes, micro-electro-mechanical (MEMS) switches. Many reconfigurable antennas were proposed by many researchers with reconfigurability in frequency as well as pattern. Most of these antennas switch between multiband, narrow band and ultra-wide bands using the features of frequency reconfiguration. An ultra-wide band antenna with notch band reconfigurability was proposed in [1]. In this proposed model, two PIN diodes are incorporated to achieve switchable single notch bands. In [2], a tunable notch band ( 2.7 to $7.2 \mathrm{GHz}$ ) antenna was proposed by the authors using diversity filtering band feature. Parisa Lotf et. al. [3] proposed a dual/triple notch reconfigurable antenna using patch circular rotational motion. A reconfigurable UWB antenna that rejects WLAN signals in the range of $5.15-5.825 \mathrm{GHz}$ on demand using MEMS switch was proposed in [4]. UWB frequency reconfigurable antennas were proposed by various authors using PIN diodes in [5-10] for applications like cognitive radio, WLAN etc. In this paper, a frequency reconfigurable UWB monopole antenna with dual band notch characteristics is proposed. Frequency reconfiguration is achieved through the placement of PIN diodes. For various combinations of PIN diodes, multi-band, narrow band and band rejection switching is obtained. Section-II describes the placement of PIN diodes on monopole UWB dual notch antenna, simulated model and fabricated model. Section-III illustrates the antenna performance parameters such as $\mathrm{S}_{11}$ characteristics analysis for different combinations of PIN diodes, radiation patterns, gain and radiation efficiency characteristics. Section IV gives the conclusion of proposed work and the paper.

\section{RECONFIGURABLE UWB ANTENNA}


An UWB monopole antenna operating from 2.4 $18.35 \mathrm{GHz}$ with dual band notches at $3.2-3.9 \mathrm{GHz}$ (WiMAX) and $7.9-8.6 \mathrm{GHz}$ is designed with reference to [11]. The radiating patch consists of $\mathrm{H}$-slot and a pair of $\mathrm{U}$ and Inverted U-slot to achieve dual band notch characteristics. The geometrical specifications of the antenna with simulated model in HFSS are represented in Figure 1(i). To obtain reconfigurable feature in UWB antenna, two PIN diodes $\mathrm{D}_{1}$ and $\mathrm{D}_{2}$ are placed at specific locations on radiating patch of antenna as illustrated in Figure 1(i). PIN diodes act as switching components for reconfiguring frequency bands between multi-bands, narrow bands and band rejections. For different combinations of PIN diodes ON and OFF conditions, impedance bandwidth $\left(\mathrm{S}_{11}<-10 \mathrm{~dB}\right)$ is obtained through simulation and experimentation. Proposed antenna is fabricated on FR-4 substrate of thickness $0.8 \mathrm{~mm}$ and dielectric constant 4.4. Figure 1(ii) presents fabricated proposed antenna top view. For different combinations of PIN diodes ON and OFF conditions, impedance bandwidth $\left(\mathrm{S}_{11}<-10 \mathrm{~dB}\right)$ is obtained through simulation and experimentation.

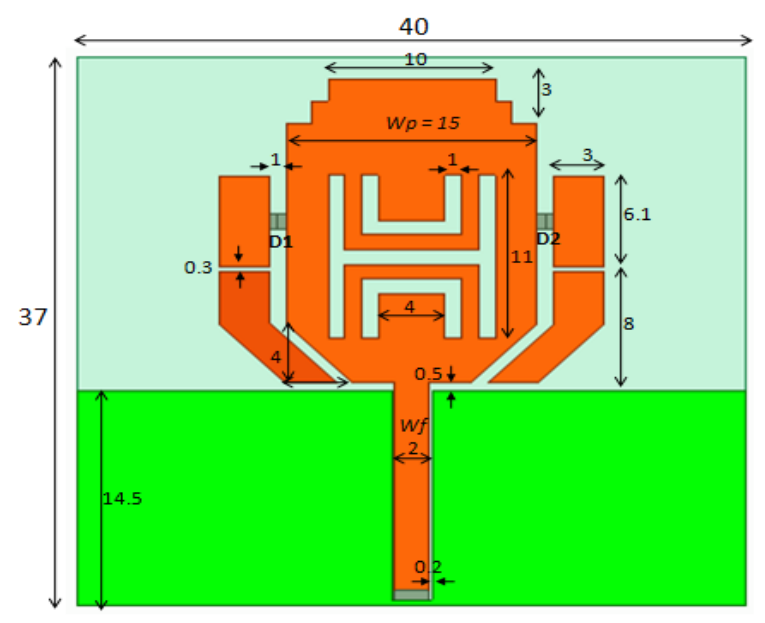

(i) Proposed antenna

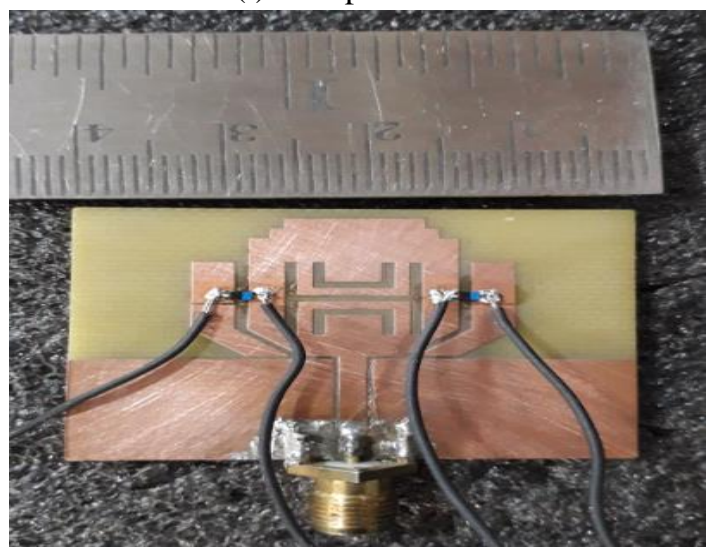

(ii) Fabricated antenna top view

Fig.1. UWB monopole antenna and placement of PIN diodes

\section{FREQUENCY RECONFIGURABILITY}

Frequency reconfigurability is achieved by switching PIN diodes D1 and D2 between ON and OFF conditions. Basic UWB antenna operates from $2.4-18.3 \mathrm{GHz}$ with dual notches at $3.7 \mathrm{GHz}$ and $8.3 \mathrm{GHz}$. By switching D1 and D2 components ON and OFF, this dual notch UWB is reconfigured to multiband, narrow band and band rejection. Figure 2(i) illustrates $S_{11}$ characteristics of proposed reconfigurable antenna for $\mathrm{D} 1=\mathrm{D} 2=\mathrm{OFF}$ and $\mathrm{D} 1=\mathrm{OFF}, \mathrm{D} 2=\mathrm{ON}$ conditions in comparison with basic antenna $S_{11}$ characteristics. For $\mathrm{D} 1=\mathrm{D} 2=\mathrm{OFF}$ condition, proposed antenna is operating for dual band from 4.156.99GHz and 15.24-18.07GHz. For D1=OFF and D2=ON 
condition, proposed antenna is operating from 4.23$10.34 \mathrm{GHz}$ and $15.11-18.25 \mathrm{GHz}$. By switching D1 to ON condition, proposed antenna operates for radar/military applications which were notched by basic antenna. Figure 2(ii) represents $S_{11}$ characteristics of proposed antenna for $\mathrm{D} 1=\mathrm{ON}, \quad \mathrm{D} 2=\mathrm{OFF}$ and $\mathrm{D} 1=\mathrm{D} 2=\mathrm{ON}$ conditions. $\mathrm{S}_{11}$ characteristics are almost identical for D1 $=\mathrm{OFF}, \mathrm{D} 2=\mathrm{ON}$ and $\mathrm{D} 1=\mathrm{ON}, \mathrm{D} 2=\mathrm{OFF}$ conditions due to symmetry. For $\mathrm{D} 1=\mathrm{D} 2=\mathrm{ON}$ condition, proposed antenna operates for triple band from $3.45-3.87 \mathrm{GHz}, 6.02-12.45 \mathrm{GHz}$ and 14.26-17.49GHz.

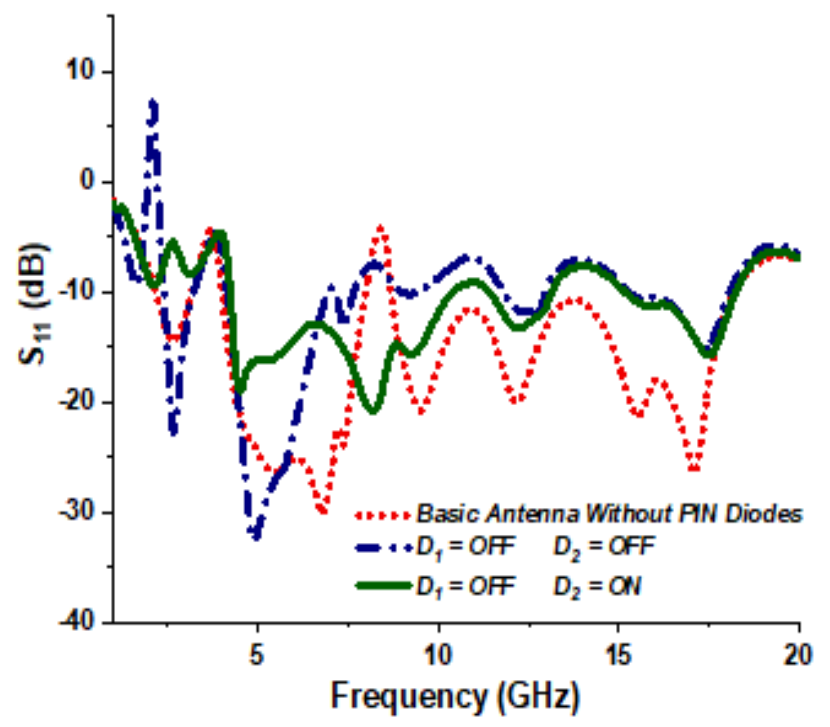

(i) D1 = OFF condition

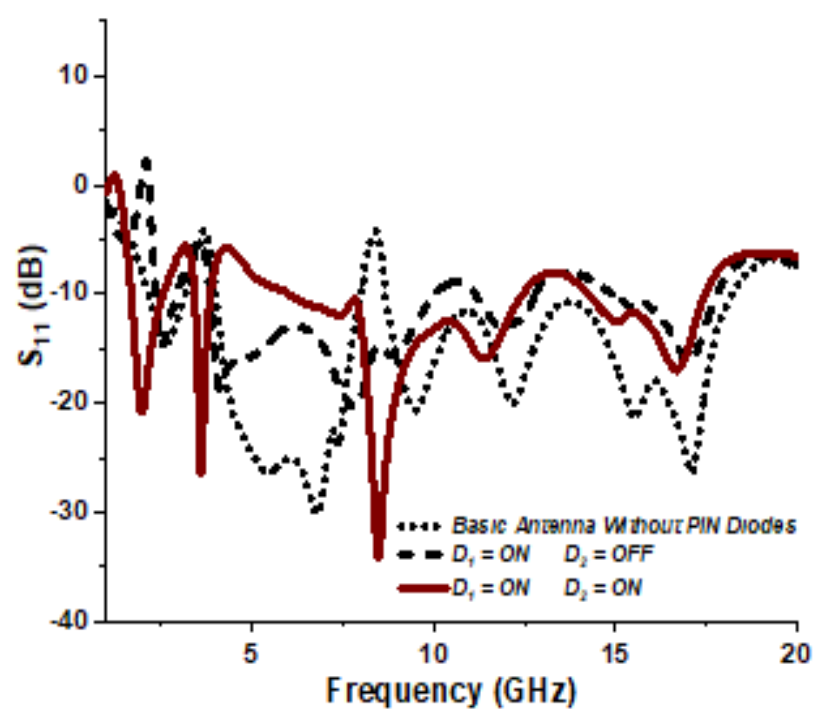

(ii) $\mathrm{D} 1=\mathrm{ON}$ condition

Fig.2. Simulated $S_{11}$ characteristics of proposed reconfigurable antenna

It is observed that for this condition, it operates at narrow band for WLAN applications and band rejects for WiMAX/DSRC applications. Operating bands obtained for different combinations of D1 and D2 ON OFF conditions are tabulated in table 1. Figure 3(i) and 3(ii) illustrate simulated and measured $S_{11}$ characteristics of proposed reconfigurable antenna for D1 and D2 ON-OFF conditions. Simulated and experimental characteristics are in good agreement. 
Table 1: Operating bands of proposed reconfigurable antenna

\begin{tabular}{|cc|l|c|}
\hline D1 & D2 & Operating Bands (GHz) & $\begin{array}{c}\text { No. of } \\
\text { Bands }\end{array}$ \\
\hline 0 & 0 & $4.15-6.99,15.24-18.07$ & 2 \\
\hline 0 & 1 & $4.23-10.34,15.11-18.25$ & 2 \\
\hline 1 & 0 & $3.84-10.08,14.95-17.72$ & 2 \\
\hline 1 & 1 & $\begin{array}{l}3.45-3.87,6.02-12.45,14.26- \\
17.49\end{array}$ & 3 \\
\hline
\end{tabular}

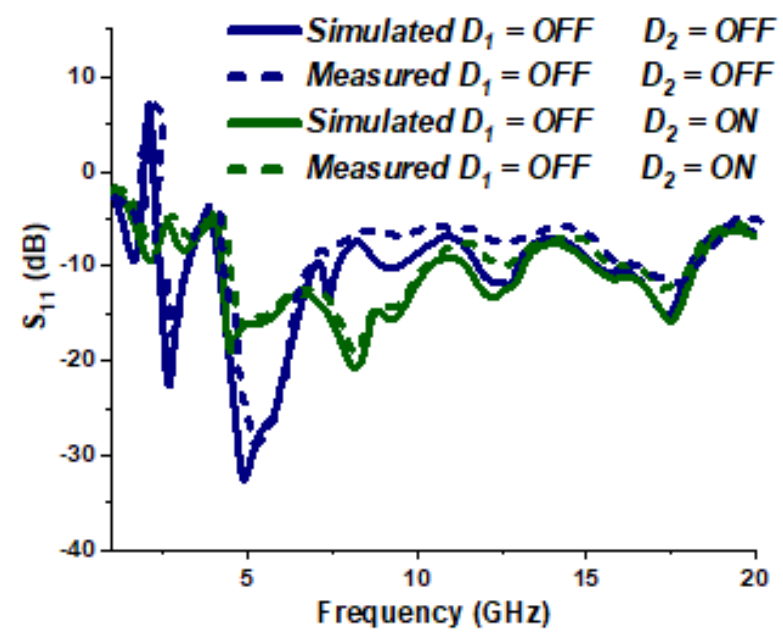

(i) $\mathrm{D} 1=$ OFF condition

15.5GHz and $8.3 \mathrm{GHz}$ respectively. H-plane and E-plane radiation patterns of proposed antenna are represented in Figure 5 and 6 for different switching combinations of D1 and D2 diodes. It is observed that radiation patterns are directional in nature.

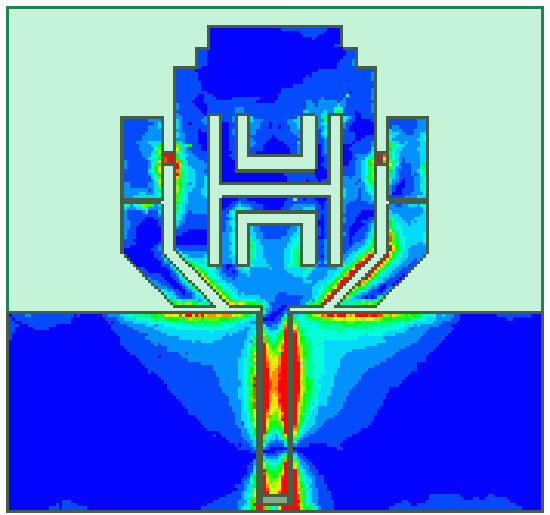

(i) $\mathrm{D} 1=\mathrm{D} 2=\mathrm{OFF}$ at $15.5 \mathrm{GHz}$

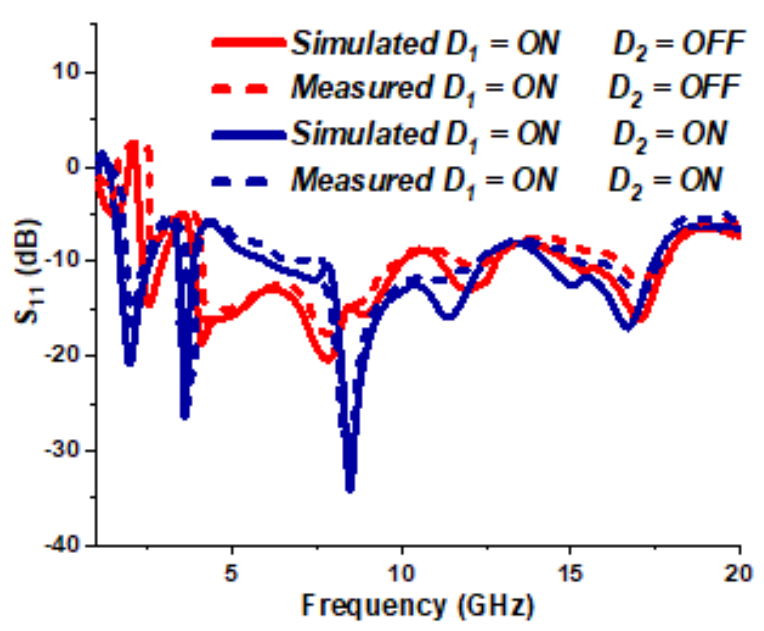

(ii) $\mathrm{D} 1=\mathrm{ON}$ condition

Fig.3. Simulated and measured $\mathrm{S}_{11}$ characteristics of proposed reconfigurable antenna

Figure 4 (i) and (ii) illustrate surface current distribution of proposed antenna for $\mathrm{D} 1=\mathrm{D} 2=\mathrm{OFF}$ and $\mathrm{ON}$ conditions at

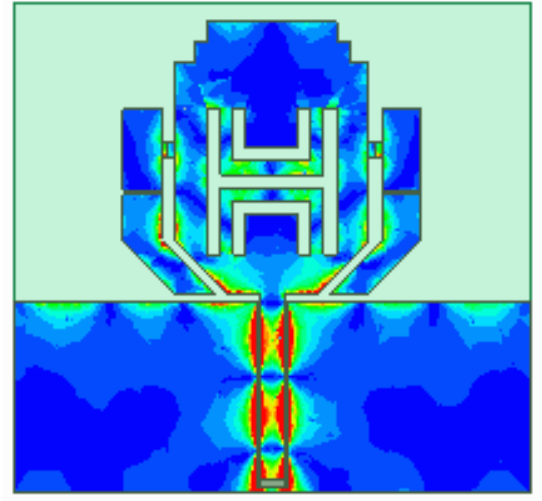

(ii) $\mathrm{D} 1=\mathrm{D} 2=\mathrm{ON}$ at $8.3 \mathrm{GHz}$

Fig.4. Surface current distribution of proposed antenna 


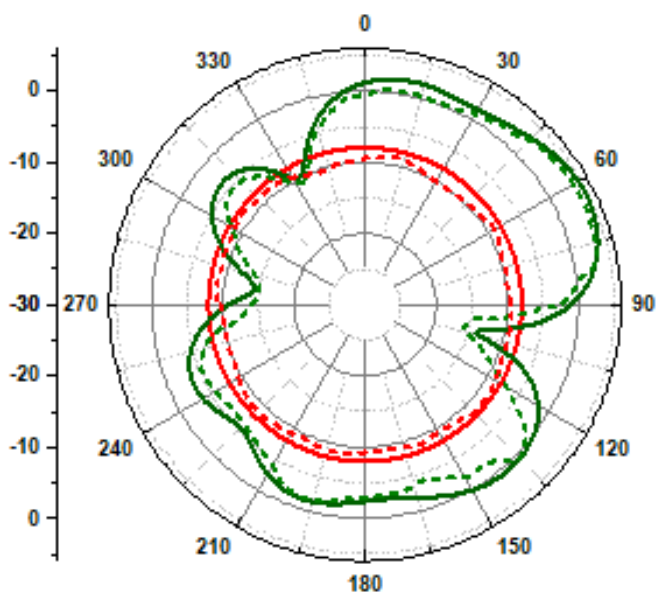

(i) $8.3 \mathrm{GHz}$ for $\mathrm{D} 1=\mathrm{D} 2=\mathrm{ON}$

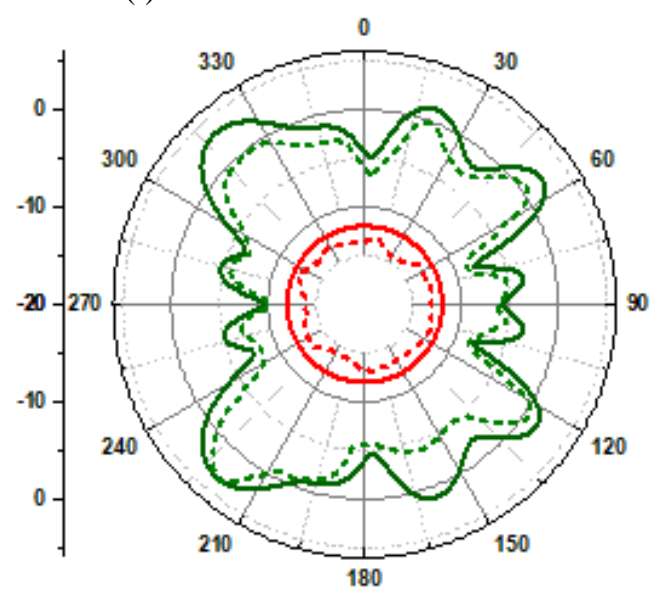

(ii) $15.5 \mathrm{GHz}$ for $\mathrm{D} 1=\mathrm{ON} \mathrm{D} 2=\mathrm{OFF}$

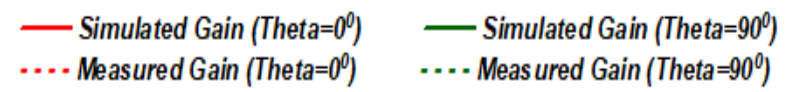

Fig.5. Radiation patterns of proposed antenna in H-Plane

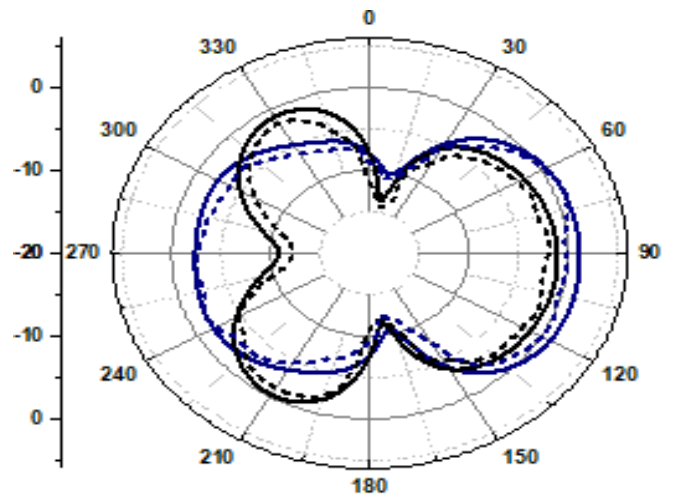

(i) $8.3 \mathrm{GHz}$ for $\mathrm{D} 1=\mathrm{D} 2=\mathrm{ON}$

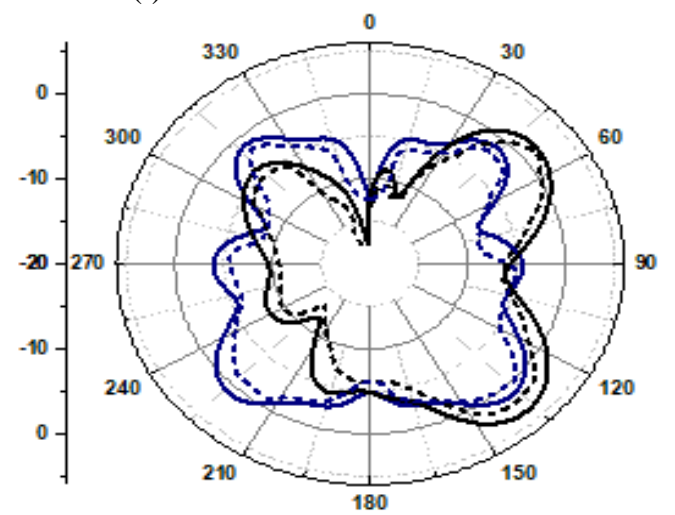

(ii) $15.5 \mathrm{GHz}$ for $\mathrm{D} 1=\mathrm{ON} \mathrm{D} 2=\mathrm{OFF}$

- Simulated Gain $\left(P h i=0^{0}\right)$ -... Measured Gain $\left(P h i=0^{0}\right)$

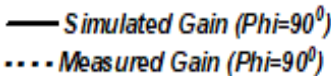

Fig.6. Radiation patterns of proposed antenna in E-Plane

Measured peak gain characteristics of proposed antenna are presented in Figure 7 for various switching combinations of diodes D1 and D2. It is observed that gain is low at low frequencies and increases with frequency. Measured radiation efficiency characteristics of proposed antenna are illustrated in Figure 8 and radiation efficiency decreases with increase in frequency. For different D1 and D2 combinations, peak gain obtained at $15.5 \mathrm{GHz}$ and corresponding radiation efficiency (\%) are tabulated in Table 2. 


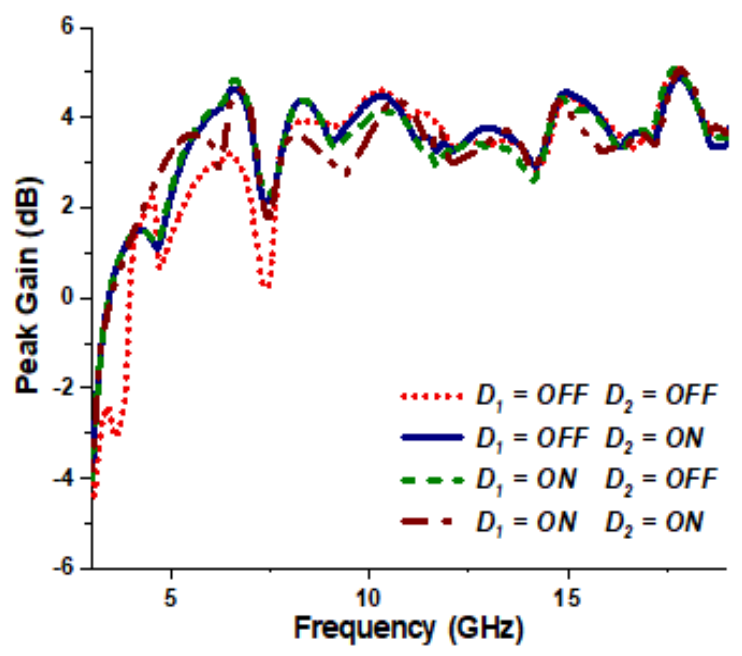

Fig.7. Peak gain characteristics of proposed antenna

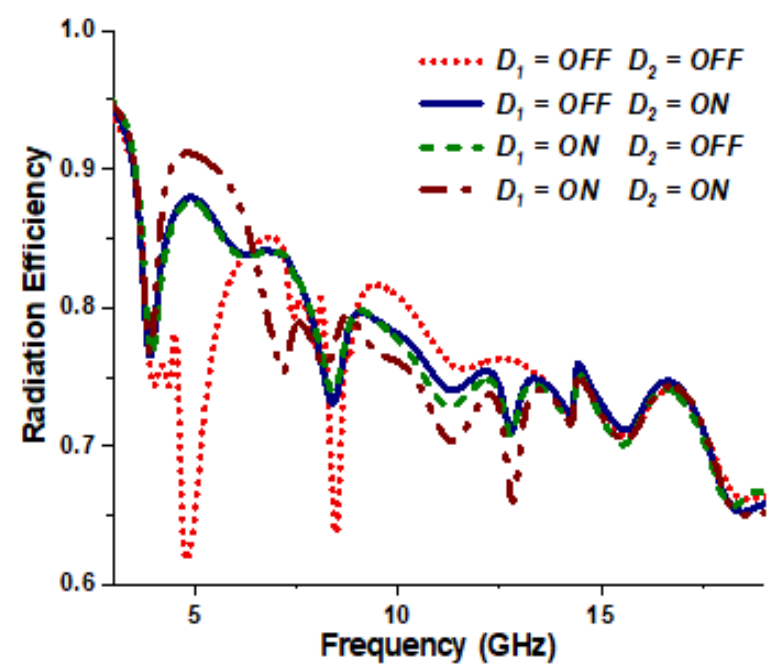

Fig.8. Radiation efficiency characteristics of proposed antenna

Table 2: Peak gain and radiation efficiency of proposed reconfigurable antenna at $15.5 \mathrm{GHz}$

\begin{tabular}{|cc|c|c|}
\hline D1 & D2 & $\begin{array}{c}\text { Peak Gain } \\
(\mathbf{d B})\end{array}$ & $\begin{array}{c}\text { Radiation } \\
\text { Efficiency } \\
(\boldsymbol{\%})\end{array}$ \\
\hline 0 & 0 & 3.58 & 70.7 \\
\hline 0 & 1 & 4.12 & 71.1 \\
\hline 1 & 0 & 4.23 & 70.0 \\
\hline 1 & 1 & 4.30 & 70.3 \\
\hline
\end{tabular}




\section{CONCLUSION}

A frequency reconfigurable UWB antenna using PIN diodes as switching components is proposed in this paper. Frequency reconfigurability is achieved by placing two PIN diodes D1 and D2 in radiating element. By switching the diodes D1 and D2 between ON and OFF conditions, operating bands are reconfigured to multiband and narrowband. Proposed reconfigurable antenna can switch between UWB, WIMAX/DSRC, RADAR/Military and $\mathrm{Ku}$ band applications. $\mathrm{S}_{11}$ characteristics for different diode combinations are analyzed in this paper. Antenna parameters like surface current distribution, radiation patterns, gain and radiation efficiency characteristics are investigated experimentally. Simulation and measured results are in good agreement.

\section{REFERENCES}

[1] Nasrin Tasouji, Javad Nourinia, Changiz Ghobadi, Farzad Tofigh, “A Novel Printed UWB Slot Antenna With Reconfigurable Band-Notch Characteristics", IEEE Antennas and Wireless Propagation Letters, Vol. 12, pp. 922-925, 2013.

[2] [Sajjad Abazari Aghdam, "Reconfigurable Antenna with a Diversity Filtering band Feature Utilizing Active Devices for Communication Systems", IEEE Transactions on Antennas and Propagation, Vol. 61 , pp. 5223 - 5228, Oct. 2013.

[3] [Parisa Lotfi, Mohammadnaghi Azarmanesh, Saber Soltani, "Rotatable Dual Band-Notched UWB/Triple-Band WLAN Reconfigurable Antenna", IEEE Antennas and Wireless Propagation Letters, Vol. 12, pp. 104-107, 2013.

[4] Dimitris E. Anagnostou, Michael T. Chryssomallis, Benjamin D. Braaten, John L. Ebel, Nelson Sepúlveda, "Reconfigurable UWB Antenna With RF-MEMS for On-Demand WLAN Rejection", IEEE Transactions on Antennas and Propagation, Vol. 62, no. 2, pp. 602-608, 2014.

[5] Syeda Irum Jafri, Rashid Saleem, Muhammad Farhan Shafique, Anthony Keith Brown, "Compact reconfigurable multiple-inputmultipleoutput antenna for ultra wideband applications", IET Microwaves, Antennas \& Propagation, Vol.10, pp. 413-419, 2016.

[6] Gunjan Srivastava, Akhilesh Mohan, Ajay
Chakrabarty, "Compact Reconfigurable UWB Slot Antenna for Cognitive Radio Applications", IEEE Antennas and Wireless Propagation Letters, Vol. 16, pp. 1139-1142, 2017.

[7] Homayoon Oraizi , Nooshin Valizade Shahmirzadi, "Frequency- and time-domain analysis of a novel UWB reconfigurable microstrip slot antenna with switchable notched bands", IET Microwaves, Antennas \& Propagation, Vol.11, pp. 1127-1132, 2017.

[8] JingYa Deng, Simin Hou, Luyu Zhao, LiXin Guo, "Wideband-to-Narrowband Tunable Monopole Antenna with Integrated Band-pass Filters for UWB/WLAN Applications", IEEE Antennas and Wireless Propagation Letters, Vol. 16, pp. 2734 - 2737, 2017.

[9] Mahmoud Shirazi, Tianjiao Li, Junyi Huang, Xun Gong, "A Reconfigurable Dual-Polarization Slot-Ring Antenna Element with Wide Bandwidth for Array Applications", IEEE Transactions on Antennas and Propagation, Vol. 66, no. 2, pp. 5943 - 5954, 2018.

[10]Md Shahidul Alam, Amin Abbosh, "Reconfigurable band-rejection antenna for ultra-wideband applications", IET Microwaves, Antennas \& Propagation, Vol.12, pp. 195 - 202, 2018.

[11] Vutukuri Sarvani Duti Rekha, Pokkunuri Pardhasaradhi, Boddapati Taraka Phani Madhav, Yalavarthi Usha Devi, "Dual Band Notched CPW Fed Printed Monopole Antenna for UWB Applications", International Journal of Intelligent Engineering and Systems, Vol.13, no.3, pp. 26-32, 2020. 